\title{
Establishment of a benign meningioma cell line by hTERT-mediated immortalization
}

\author{
Sylvia Püttmann ${ }^{1}$, Volker Senner ${ }^{1}$, Stephan Braune ${ }^{1}$, Beate Hillmann ${ }^{1}$, Rita Exeler ${ }^{2}$, \\ Christian H Rickert ${ }^{1}$ and Werner Paulus ${ }^{1}$ \\ ${ }^{1}$ Institute of Neuropathology, University Hospital, Münster, Germany and ${ }^{2}$ Institute of Human Genetics, \\ University Hospital, Münster, Germany
}

\begin{abstract}
Meningioma represents the most common intracranial tumor, but well-characterized cell lines derived from benign meningiomas are not available. A major reason for the lack of benign tumor cell lines is senescence of nonmalignant cells in vitro, while malignant cells are often immortal. We have developed a meningioma cell line by retrovirally transducing primary cells derived from a human WHO grade I meningothelial meningioma with the human telomerase reverse transcriptase (hTERT) gene, which enables bypassing cellular senescence. Five clones have been cultured for more than $\mathbf{2 1}$ months so far, while corresponding nontransfected cells ceased proliferation within 3 months. Quantitative RT-PCR and a telomeric repeat amplification protocol (TRAP) assay revealed high hTERT mRNA levels and high telomerase activity in all transduced populations, while nontransduced cells were negative. The average telomere size of transduced cells was considerably longer than that of parental cells and the biopsy specimen. One clone, designated Ben-Men-1, was characterized in more detail, and exhibited typical cytological, immunocytochemical, ultrastructural and genetical features of meningioma, including whorl formation, expression of epithelial membrane antigen, desmosomes and interdigitating cell processes, as well as -22q. Following subdural transplantation into nude mice, tumor tissue with typical histological features of meningothelial meningioma was found. We conclude that Ben-Men-1 represents an immortalized yet differentiated cell line useful for biological and therapeutical studies on meningioma.

Laboratory Investigation (2005) 85, 1163-1171. doi:10.1038/labinvest.3700307; published online 20 June 2005
\end{abstract}

Keywords: cell line; immortalization; hTERT; meningioma; telomerase

Meningiomas arise from meningothelial (arachnoidal cap) cells and constitute approximately $20 \%$ of all intracranial tumors. About $85 \%$ of meningiomas are benign (grade I), while $10 \%$ are atypical (grade II) and $3-5 \%$ malignant (anaplastic, grade III). ${ }^{1} \mathrm{~A}$ few cell lines derived from malignant meningiomas have been described, ${ }^{2-4}$ but no well-characterized cell line originating from a benign meningioma is available so far. The lack of differentiated cell lines of these common neoplasms impairs experimental studies on molecular pathogenesis, biological features and new adjuvant therapies. The major reason for the difficulty in generating permanent cell lines of benign tumors is replicative senescence, which is in part due to low or absent telomerase activity and subsequent progressive shortening of telomeres with each cell cycle, whereas malignant tumor cells show

Correspondence: Dr W Paulus, MD, Institute of Neuropathology, University Hospital, Domagkstr. 19, Münster D-48129, Germany. E-mail: werner.paulus@uni-muenster.de

Received 20 April 2005; revised and accepted 17 May 2005; published online 20 June 2005 high telomerase activity enabling them to undergo unlimited growth. ${ }^{5,6}$ Accordingly, telomerase activity is directly related to grade of malignancy in meningiomas, with the vast majority of grade I tumors being negative and virtually all grade III tumors being positive. ${ }^{7-9}$ Transferring the gene for human telomerase reverse transcriptase (hTERT), the catalytic subunit and limiting factor of telomerase, into non-neoplastic cells and benign tumor cells has resulted in immortalized cell lines of a variety of cell types. ${ }^{10-16}$ Here, we report on establishment of the immortalized, yet differentiated Ben-Men-1 cell line derived from a benign meningioma by retroviral expression of hTERT.

\section{Materials and methods}

Isolation and Culture of Primary Human Meningioma Cells

Tumor cells originated from a meningothelial meningioma (grade I, WHO, \#1238-03) attached to the parietal falx of a 68-year-old female patient who 
underwent surgery at Münster University Hospital. At $20 \mathrm{~min}$ after surgical resection tumor tissue was cut into small pieces and suspended in DMEM supplemented with $10 \%$ fetal bovine serum, $100 \mathrm{U} /$ $\mathrm{ml}$ penicillin $\mathrm{G}$ and $0.01 \mathrm{mg} / \mathrm{ml}$ streptomycin sulfate (all from Biochrom, Berlin, Germany). Cells were grown on uncoated plastic tissue culture dishes (Greiner, Solingen, Germany) at $37^{\circ} \mathrm{C}$ in a $5 \% \mathrm{CO}_{2}$ humidified atmosphere. Confluent cultures were split by using $0.05 \%$ trypsin/EDTA (Biochrom). Medium was changed twice a week.

\section{Retroviral Vectors, Transduction and Selection}

The retroviral plasmid pLNCX2-hTERT was constructed by inserting the hTERT coding sequence into pLNCX2 containing a neomycin resistance gene (BD Biosciences Clontech, Heidelberg, Germany). pCI-Neo-hTERT ${ }^{17}$ was cut with EcoRI, filled in using Klenow enzyme and cut with SalI to release hTERT cDNA. pLNCX2 was cut with HindIII, filled in and cut with SalI. pLNCX2-hTERT was transfected into the amphotropic packaging cell line Phoenixampho $^{18}$ (obtained from Dr Gary Nolan, Stanford University Medical Center, CA, USA) using the Effectene Transfection Reagent (Qiagen, Hilden, Germany). After $24 \mathrm{~h}$ the supernatant was collected and retroviral particles were harvested by filtering through a $0.45 \mu \mathrm{m}$ filter (Schleicher and Schuell, Dassel, Germany). Second passage meningioma cells were seeded in $60 \mathrm{~mm}$ culture dishes at a density of $5 \times 10^{5} \mathrm{cells} / \mathrm{dish}$. The next day cells were transduced by incubation with viral supernatant supplemented with $4 \mu \mathrm{g} / \mathrm{ml}$ polybrene (Sigma-Aldrich Chemie, Munich, Germany) for $24 \mathrm{~h}$. After $72 \mathrm{~h}$ the medium was changed and cells were selected with $350 \mu \mathrm{g} / \mathrm{ml}$ G418 (PAA Laboratories, Cölbe, Germany) for 8 weeks. Control experiments using retroviral transduction of a green fluorescent protein (GFP) marker gene revealed transduction efficiencies of about $65 \%$. Five clones were isolated and maintained for further investigations.

\section{Telomerase Analysis}

mRNA levels were quantified by LightCycler Telo TAGGG hTERT Quantification kit (Roche Diagnostics, Mannheim, Germany) using the LightCycler System (Roche). Telomerase activity was measured using a telomeric repeat amplification protocol (TRAP) assay (Telomerase PCR ELISA kit, Roche). Telomere length was determined by Southern blot analysis of telomere restriction fragments using the TeloTAGGG Telomere Length Assay kit (Roche). All assays were performed as triplicates and repeated at least twice.

\section{Growth Kinetics}

Doubling time was determined by counting cells at daily intervals. First day $1 \times 10^{5}$ cells were seeded on culture dishes. At 24, 48, 72, 96 and $120 \mathrm{~h}$ following plating, cells were trypsinized and counted by using a cell counter (CASY Cell Counter, Schärfe System, Reutlingen, Germany). For each calculation cells from two dishes were used. Doubling time was calculated from the data obtained at the logarithmic growth phase.

\section{Immunocytochemistry}

Cells were cultured in four-well Lab-Tek ${ }^{\mathrm{TM}}$ glass chamber slides (Nunc, Wiesbaden, Germany). After $24 \mathrm{~h}$ the cells were washed with PBS and fixed in buffered $3.7 \%$ paraformaldehyde in PBS for $10 \mathrm{~min}$. Cells were stained in a Horizon TechMate apparatus (Dako, Hamburg, Germany) using the DAB-system kit and mouse monoclonal antibodies against glial fibrillary acidic protein (GFAP, 1:4000), vimentin (1:100), epithelial membrane antigen (EMA, 1:200), progesterone receptor (1:100), estrogen receptor (1:25), cytokeratins (clone KL1, 1:75) and Ki-67 (clone MIB-1, 1:100). All antibodies were purchased from Dako.

\section{Electron Microscopy}

Cultured cells were trypsinized, washed with PBS two times, fixed with $2.5 \%$ glutaraldehyde, postfixed with 1\% osmium tetroxide, embedded in Epon and cut ultrathin. Specimens were stained with uranyl acetate and lead citrate and examined with a Zeiss EM910 electron microscope.

\section{Genetic Analysis}

Karyotyping was performed according to standard cytogenetic techniques, including G-banding. DNA was isolated from cultured cells and from paraffinembedded materials by using DNeasy Tissue kit (Qiagen). Comparative genomic hybridization (CGH) analysis was performed as previously described. ${ }^{19}$

\section{Intracranial Transplantation Experiments}

Cells were intracranially implanted into five male nu/nu CD-1 athymic nude mice (Charles River, Sulzfeld, Germany) aged 8 weeks using a stereotactic frame (Narashige, Tokyo, Japan). ${ }^{20}$ One million Ben-Men-1 cells in a total volume of $4 \mu \mathrm{l}$ PBS were subdurally injected with a Hamilton syringe at $4 \mathrm{~mm}$ anterior to the interaural line, $2.5 \mathrm{~mm}$ lateral to the midline, in a depth of $1.2 \mathrm{~mm}$. The designation 'sudural' here refers to a location beneath the dura, that is, between dura and the brain, rather than to the virtual subdural space proper (between dura and arachnoidal cap cells) that cannot be targeted by stereotaxy. A relatively long survival period of 107 days was selected, because we expected slow tumor growth. Animals were killed, brains were removed 
and fixed in $3.7 \%$ buffered paraformaldehyde in PBS. Brains were embedded in paraffin, sectioned at $2 \mu \mathrm{m}$ and stained with $\mathrm{H} \& \mathrm{E}$ as well as by using immunohistochemistry as described above.

\section{Results}

\section{Transduction and Selection of Meningioma Cells}

Following retroviral infection, transduced cells were selected with neomycin for 8 weeks, while neomycin-treated, nontransduced primary cells died after 2 weeks. Five neomycin-resistant clones were further characterized. One of them, called BenMen-1, was additionally analyzed for ultrastructural, immunocytochemical and genetic features as well as tumor formation in vivo (see below).

\section{Telomerase Analysis}

Quantitative RT-PCR revealed that all transduced meningioma populations expressed high amounts of hTERT mRNA, whereas virtually no message was detectable in nontransduced parental cells (Figure 1a). Correspondingly, TRAP assays showed high telomerase activity in transduced cells, but no activity in nontransduced parental cells (Figure 1b). Telomerase activity was repeatedly measured and remained stable over 18 months so far. Using Southern blot analysis of telomere restriction fragments, the average telomere size of transduced meningioma populations was in the range of 16$21 \mathrm{~kb}$ and considerably longer than that of parental cells and the biopsy specimen which showed a wide variability of telomere length with a peak of about $4.0 \mathrm{~kb}$ (Figure 1c), indicating that ectopic expression of hTERT had elongated telomeres.

\section{Morphological Analysis}

After 2-3 months, nontransduced meningioma cells underwent progressive morphological change reflecting senescence, including absent proliferation, enlargement, polymorphism, multinucleation and detachment (Figure 2b). In contrast, transduced meningioma cells of all five clones did not change morphology; they were homogeneous in shape and continued to proliferate for now more than 23 months (Figure 2a). Electron microscopy of BenMen-1 cells showed typical ultrastructural features of meningothelial cells, including desmosomes (Figure 2c) and interdigitating cellular processes (Figure 2d). Immunocytochemistry revealed expression of epithelial membrane antigen (Figure 3a) and vimentin (Figure $3 \mathrm{~b}$ ) in all transduced meningioma populations, while GFAP, cytokeratins, progesterone and estrogen receptors were absent. This expression pattern corresponded to that of the original biopsy specimen (Figure 3c, d).

\section{Growth Kinetics}

Average doubling time of Ben-Men-1 cells was $25.6 \mathrm{~h}$. Repeated analyses did not reveal significant changes in growth kinetics with time.

\section{In Vivo Experiments}

Subarachnoidal tumor tissue was found 107 days after transplantation of Ben-Men-1 cells. Histopathologically, tumor tissue with typical features of human benign (grade I) meningioma was encountered (Figure 3e, f), including absence of mitoses, nuclear monomorphism, nuclear cytoplasmic invaginations, whorl formations, absence of brain invasion and absence of apparent distant metastases. A few lymphocytic infiltrates were seen. Multiple tumors were not encountered. Immunohistochemically, tumor cells were positive for vimentin and epithelial membrane antigen (Figure $3 \mathrm{~g}$ ), while cytokeratins and GFAP were not expressed. Ki-67 labeling index was less than $1 \%$.

\section{Genetic Analysis}

CGH of both the original tumor specimen and Ben-Men-1 cells revealed $-22 q$ as the sole chromosomal imbalance (Figure 3h). Karyotyping of 10 metaphases of Ben-Men-1 cells confirmed loss of one chromosome 22 in all cells, while other chromosomal changes were absent $(45, \mathrm{XX},-22$; not shown).

\section{Discussion}

We have transduced primary benign meningioma cells with the hTERT gene, resulting in increased telomerase activity, elongated telomere length and extension of life span. Nontransduced parental cells showed no telomerase activity and senesced after 3 months, whereas transduced cells have been maintained in culture for now more than 23 months without decreasing growth kinetics. Ben-Men-1 cells showed distinct ultrastructural and immunocytochemical meningothelial differentiation. Their loss of chromosome 22 as demonstrated by karyotyping and CGH is a typical genetic feature of meningioma. Furthermore, subdural xenotransplantation showed classical histological features of benign meningioma. Ben-Men-1 thus represents an immortalized yet differentiated meningioma cell line.

\section{Previously Published Meningioma Cell Lines}

Following the first trials to culture human meningioma cells in the 1920s in Cushing's laboratory, the general experience of virtually all subsequent approaches up to now has been that benign 

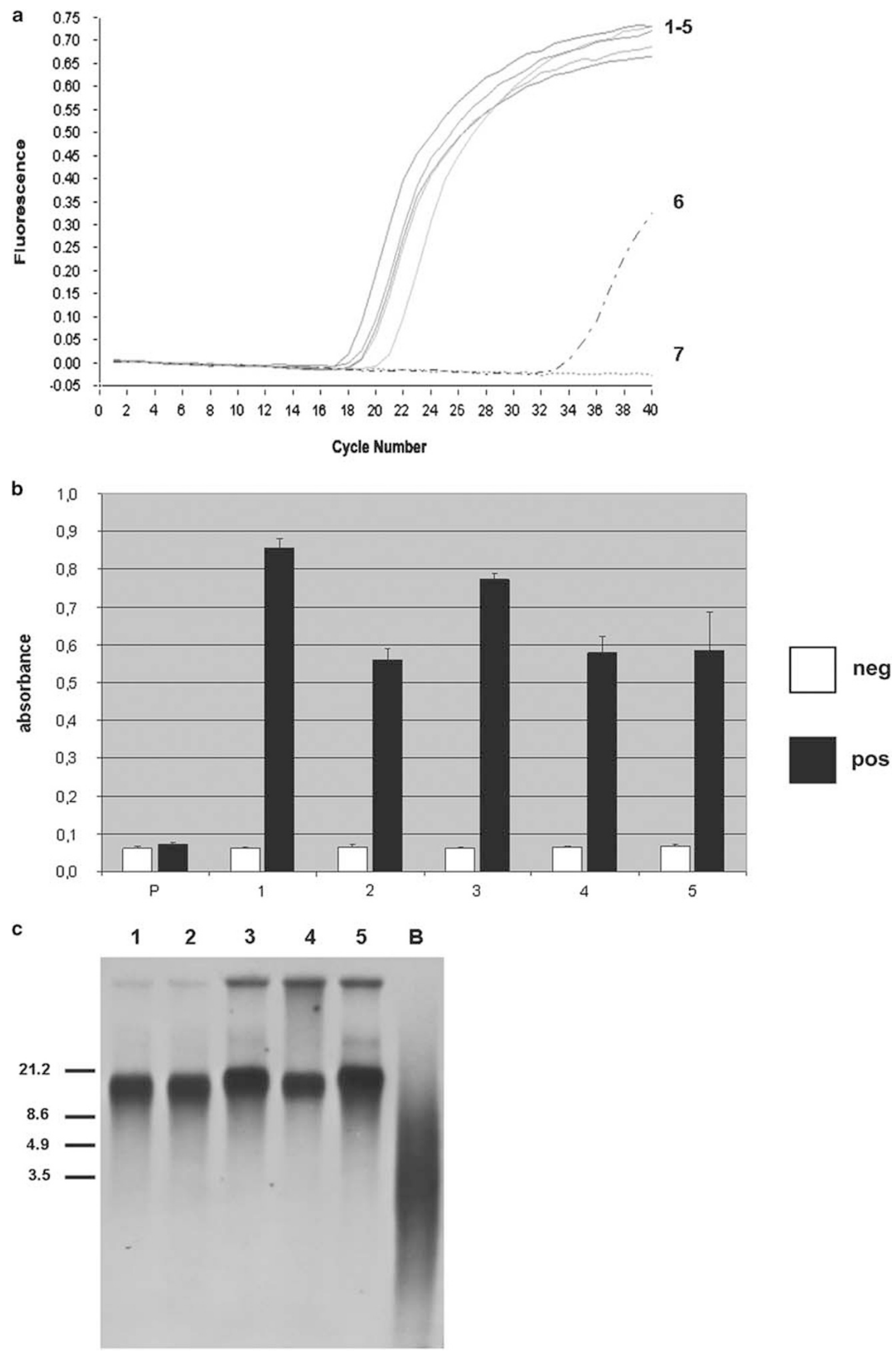
meningioma cells placed into cell culture may grow vigorously in early passages, but eventually cease proliferation, undergo senescence and do not give rise to permanent cell lines. ${ }^{2,21}$ In contrast, a few immortal cell lines derived from human malignant meningeal tumors have been established and subsequently used in several studies, including IOMMLee, F5 and KT21-MG1. ${ }^{2,32-24}$ These cell lines
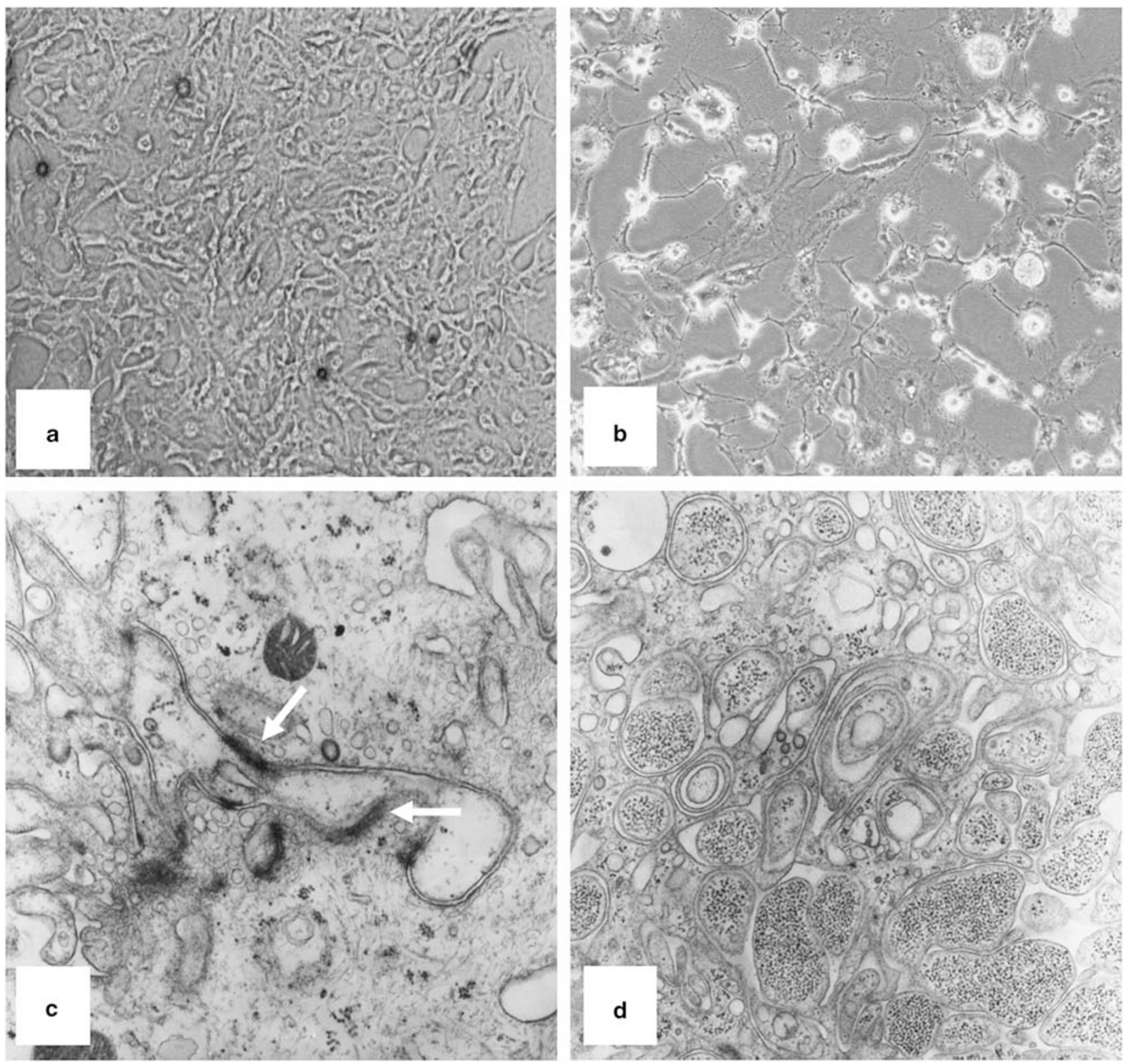

Figure 2 Morphological analysis in vitro. (a and b) Phase contrast microscopy showing that transduced cells are monomorphic and densely growing (a), while nontransduced parental meningioma cells after identical time in cell culture exhibit features of senescence, including rounding, detachment and enlargement (b). (c and d) Electron microscopy of Ben-Men-1 cells in monolayer culture showing characteristic ultrastructural features of meningothelial cells, including desmosomes (c, arrows) and interdigitating cellular processes $(\mathbf{d})$.

Figure 1 Telomerase analysis of transduced meningioma cells. (a) Real-time reverse transcriptase-polymerase chain reaction demonstrates that five transduced meningioma clones (1-5) express high levels of hTERT transcripts, while nontransduced cells (6) show extremely low levels. 7 represents water control. (b) Telomeric repeat amplification protocol (TRAP) assay showing that all transduced populations (1-5) exhibit high levels of telomerase activity, while parental cells (P) are negative. Negative controls (open bars) represent telomerase activity following inactivation by heat. Values indicate arbitrary absorbance units. (c) Southern blot (Telomere Length Assay) showing that telomeres of all transduced populations (1-5) are much longer than that of the biopsy specimen (B). The broad band of the biopsy specimen indicates wide variability of telomere length, while transduced cells are more uniform. Note that the five clones showed very similar behavior in all telomerase assays. In (a-c), clone 3 represents Ben-Men-1 cells. 

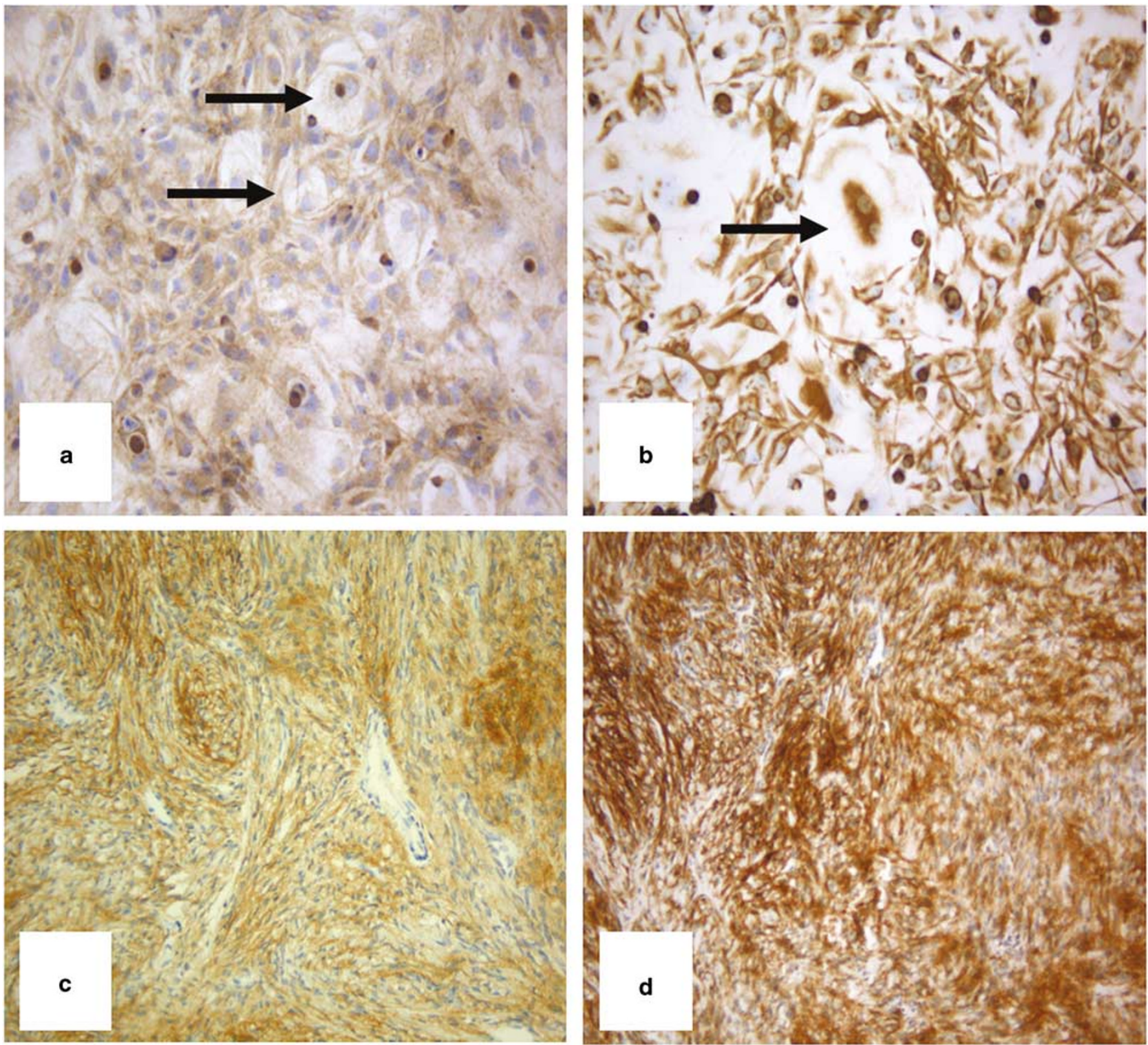

Figure 3 (a-d) Immunocytochemical analysis. Ben-Men-1 cells (a and $\mathbf{b}$ ) and cells of the original paraffin-embedded biopsy specimen (c and $\mathbf{d}$ ) are positive for epithelial membrane antigen (a and $\mathbf{c}$ ) and vimentin (b and $\mathbf{d}$ ). Note whorl formation of Ben-Men-1 cells (arrows in a and b). (e-g) Histopathology of nude mouse subdural xenotransplant showing a meningeal tumor that is well delineated from the brain (e) with a meningothelial growth pattern such as cellular whorls (f, arrow) and immunohistochemical expression of epithelial membrane antigen (g). (h) Comparative genomic hybridization (CGH) fluorescence ratio profiles of original biopsy specimen (upper) and Ben-Men-1 cells (lower) showing loss of $22 \mathrm{q}$.

exhibit malignant features in vitro and in vivo, such as dedifferentiation, anchorage-independent growth in soft agar, and invasion of mouse brain, bone and muscle. Specifically, IOMM-Lee xenografts lack typical features of meningioma such as desmosomes, expression of epithelial membrane antigen and loss of chromosome 22, while they show metastases and a very high Ki67/MIB-1 proliferation index of $30 \% .^{3,25}$ Furthermore, IOMM-Lee cells are unusal in that this cell line was established from a primary intraosseous tumor, ${ }^{26}$ and scanning electron microscopy revealed features resembling hemangio- pericytoma (previously referred to as 'hemangiopericytic meningioma'). ${ }^{3}$ Thus, it remains unclear whether IOMM-Lee cells are of meningothelial origin at all. Similarly, Korsgaard et $a 1^{22}$ described a cell line originating from a metastasizing tumor of the sacral bone and the epidural space, referred to as 'meningiosarcoma', but based on the data provided and the limited characterization possible at that time, it is questionable whether the tumor was meningothelial. Another cell line, KT21-MG1, originated from an irradiated malignant meningioma of the falx, but original tumor and xenografts did not 

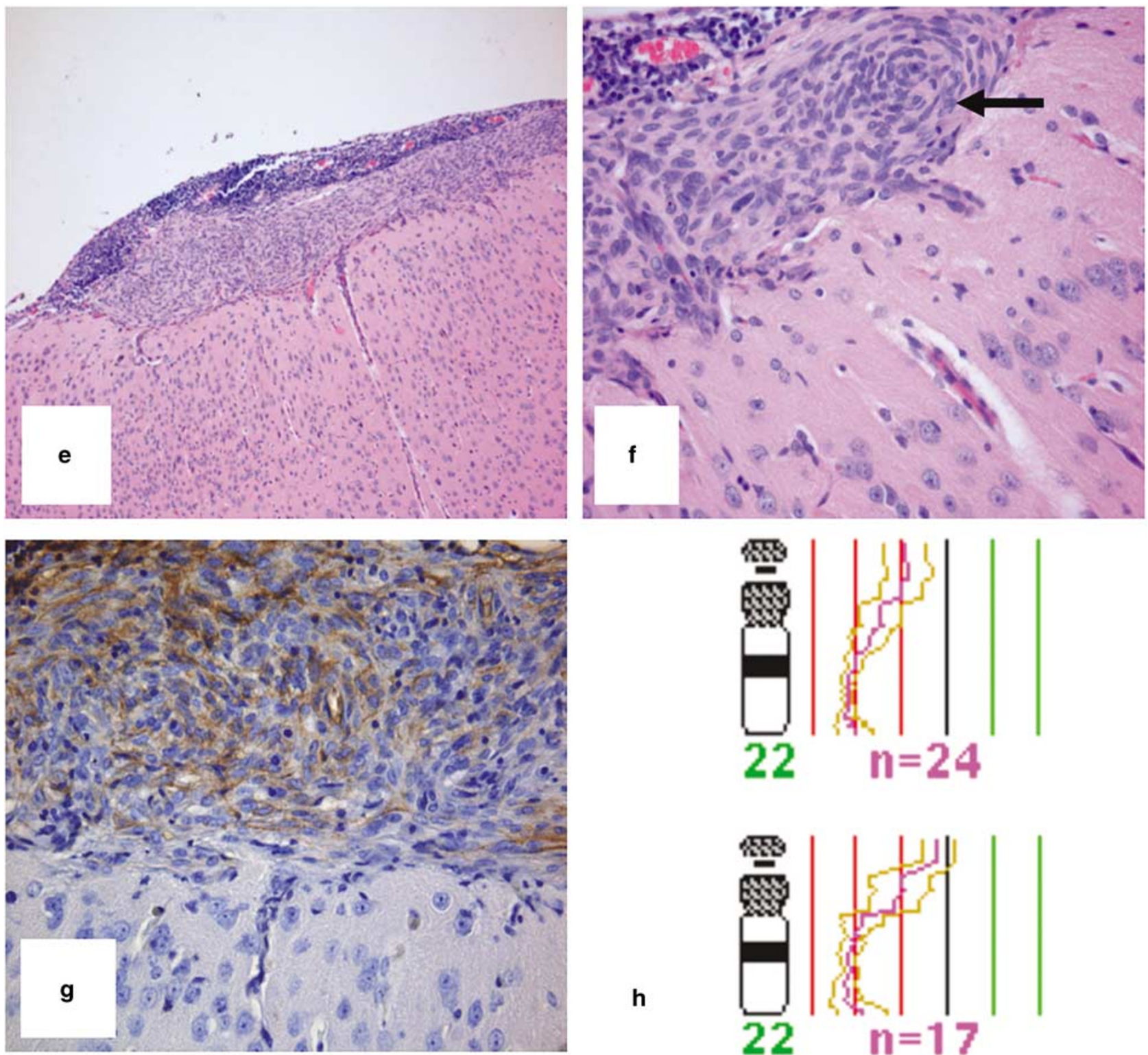

h

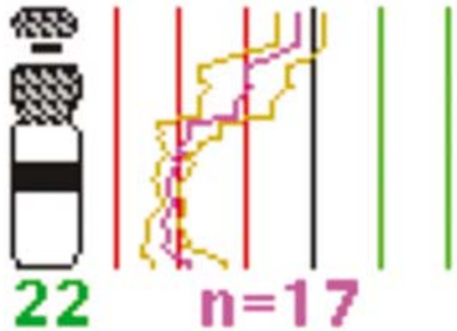

Figure 3 Continued.

show typical meningothelial differentiation except for monosomy 22 and scant desmosomes in xenografts. $^{2}$ Other meningioma cell lines have been sporadically used, such as $\mathrm{CH}-157 \mathrm{NN},{ }^{27,28}$ SF1335 ${ }^{29}$ and HBL-52 (Cell Lines Service and Cellbank, Heidelberg, Germany), ${ }^{30}$ but histopathological, immunocytochemical, electron microscopical and cell biological data for demonstrating meningothelial differentiation, grade of malignancy as well as immortality have not been published. Short-term cultures of benign meningiomas have also occasionally been referred to as meningioma cell lines, but they do not represent immortal cell lines. ${ }^{31}$ In conclusion, our literature survey did not reveal any immortal cell line that unequivocally had been established from a benign meningioma.

\section{Ben-Men-1 as a New Meningioma Model}

Although most meningiomas are benign, therapy is often limited by incomplete resection of the tumor, its disadvantageous position in the brain and missing adjuvant therapies. For understanding low-grade meningioma tumor biology as well as for developing and testing efficient therapies, there is need for not only a highly differentiated cell line, but also a representative, that is, intracranial in vivo model. While several heterotopic transplantation sites have been employed, such as subcutis, subrenal capsule and chorioallantoic membrane, orthotopic in vivo models have rarely been used. Most approaches have utilized malignant meningiomas, in particular the malignant meningioma cell lines 
mentioned above..$^{2,3,22,23,25,27}$ These models show frankly malignant, highly proliferative, invasive tumors, which may be useful for studying anaplastic meningioma. Recent efforts to establish a benign meningioma in vivo model have employed implantation of tissue blocks or cell suspensions directly from patients' biopsy material into nude mice. ${ }^{32-34}$ Specifically, subdural injection of $10^{6}$ primary cells derived from benign meningiomas produced tumors in athymic mice, and no animal harboring a tumor died within 90 days of implantation; histologically these tumors were consistent with meningioma and commonly showed a whorling pattern and no signs of atypia or malignancy. ${ }^{34}$ The major problem with these approaches is the heterogeneous, nonstandardized nature of primary cells. In a mouse model with conditional $N f 2$ gene inactivation, meningiomas occurred following Cre-mediated excision of Nf2 exon 2 in arachnoidal cells. ${ }^{35}$ However, only $30 \%$ of animals developed tumors and their location and interval were highly variable. To our knowledge, our approach is the first benign meningioma in vivo model utilizing a permanent meningioma cell line. By subdural (subarachnoidal) transplantation of Ben-Men-1 into nude mice, we were able to generate a slowly growing tumor with typical histological features of benign meningioma. Neither invasion of brain or bone nor histological features of atypia or anaplasia were encountered. Ben-Men-1 thus represents an immortalized yet differentiated cell line which should be a useful model for further biological and therapeutical studies.

\section{Acknowledgement}

We thank Beate Schröder for technical assistance. This study was supported by Interdisciplinary Center for Clinical Research (IZKF) Münster, Project G4.

\section{References}

1 Louis DN, Scheithauer BW, Budka H, et al. Pathology and genetics of tumours of the nervous system. In: Kleihues P, Cavenee WK (eds). World Health Organization Classification of Tumours. IARC Press: Lyon, France, 2000, pp 176-184.

2 Tanaka K, Sato C, Maeda Y, et al. Establishment of a human malignant meningioma cell line with amplified c-myc oncogene. Cancer 1989;64:2243-2249.

3 Lee WH. Characterization of a newly established malignant meningioma cell line of the human brain: IOMM-Lee. Neurosurgery 1990;27:389-395.

4 Tsujino K, Yamate J, Tsukamoto Y, et al. Establishment and characterization of cell lines derived from a transplantable rat malignant meningioma: morphological heterogeneity and production of nerve growth factor. Acta Neuropathol 1997;93:461-470.

5 Hiyama E, Hiyama K. Telomerase as tumor marker. Cancer Lett 2003;194:221-233.
6 Shay JW, Wright WE. Senescence and immortalization: role of telomeres and telomerase. Carcinogenesis 2005; 26:867-874.

7 Langford LA, Piatyszek MA, Xu R, et al. Telomerase activity in ordinary meningiomas predicts poor outcome. Hum Pathol 1997;28:416-420.

8 Boldrini L, Pistolesi S, Gisfredi S, et al. Telomerase in intracranial meningiomas. Int J Mol Med 2003;12: 943-947.

9 Leuraud P, Dezamis E, Aguirre-Cruz L, et al. Prognostic value of allelic losses and telomerase activity in meningiomas. J Neurosurg 2004;100:303-309.

10 Bodnar AG, Ouellette M, Frolkis M, et al. Extension of life-span by introduction of telomerase into normal human cells. Science 1998;279:349-352.

11 Yang J, Chang E, Cherry AM, et al. Human endothelial cell life extension by telomerase expression. J Biol Chem 1999;274:26141-26148.

12 MacKenzie KL, Franco S, May C, et al. Mass cultured human fibroblasts overexpressing hTERT encounter a growth crisis following an extended period of proliferation. Exp Cell Res 2000;259:336-350.

13 Schnabl B, Choi YH, Olsen JC, et al. Immortal activated human hepatic stellate cells generated by ectopic telomerase expression. Lab Invest 2002;82:323-333.

14 Carney SA, Tahara H, Swartz CD, et al. Immortalization of human uterine leiomyoma and myometrial cell lines after induction of telomerase activity: molecular and phenotypic characteristics. Lab Invest 2002;82: 719-728.

15 Morales CP, Gandia KG, Ramirez RD, et al. Characterisation of telomerase immortalised normal human oesophageal squamous cells. Gut 2003;52:327-333.

16 Roy NS, Nakano T, Keyoung HM, et al. Telomerase immortalization of neuronally restricted progenitor cells derived from the human fetal spinal cord. Nat Biotechnol 2004;22:297-305.

17 Counter CM, Meyerson M, Eaton EN, et al. Telomerase activity is restored in human cells by ectopic expression of hTERT (hEST2), the catalytic subunit of telomerase. Oncogene 1998;16:1217-1222.

18 Pollock R, Issne R, Zoller $\mathrm{K}$, et al. Delivery of a stringent dimerizer-regulated gene expression system in a single retroviral vector. Proc Natl Acad Sci USA 1997;97:13221-13226.

19 Rickert CH, Wiestler OD, Paulus W. Chromosomal imbalances in choroid plexus tumors. Am J Pathol 2002;160:1105-1113.

20 Senner V, Köhling R, Püttmann-Cyrus S, et al. A new neurophysological/neuropathological ex vivo model localizes the origin of glioma-associated epileptogenesis in the invasion area. Acta Neuropathol 2004; 107:1-7.

21 Rutka JT, Giblin J, Dougherty DV, et al. An ultrastructural and immunocytochemical analysis of lepromeningeal and meningioma cultures. J Neuropathol Exp Neurol 1986;45:285-303.

22 Korsgaard R, Clausen OPF, Thorud E. Establishment of a human meningeal cell line in culture. Anticancer Res 1984;4:83-88.

23 Yazaki T, Manz HJ, Rabkin SD, et al. Treatment of human malignant meningiomas by G207, a replicationcompetent multimutated herpes simplex virus 1 . Cancer Res 1995;55:4752-4756.

24 Surace EI, Lusis E, Murakami Y, et al. Loss of tumor suppressor in lung cancer-1 (TSLC1) expression in meningioma correlates with increased malignancy 
grade and reduced patient survival. J Neuropathol Exp Neurol 2004;63:1015-1027.

25 Van Furth WR, Laughlin S, Taylor MD, et al. Imaging of murine brain tumors using a 1.5 tesla clinical MRI system. Can J Neurol Sci 2003;30:326-332.

26 Lee WH, Tu YC, Liu MY. Primary intraosseous malignant meningioma of the skull: case report. Neurosurgery 1988;23:505-508.

27 Tsai JC, Goldman CK, Gillespie GY. Vascular endothelial growth factor in human glioma cell lines: induced secretion by EGF, PDGF-BB, and bFGF. J Neurosurg 1995;82:864-873.

28 Tsai JC, Hsiao YY, Teng LJ, et al. Comparative study on the ALA photodynamic effects of human glioma and meningioma cells. Lasers Surg Med 1999;24:296-305.

29 Goutebroze L, Brault E, Muchardt C, et al. Cloning and characterization of SCHIP-1, a novel protein interacting specifically with spliced isoforms and naturally occurring mutant NF2 proteins. Mol Cell Biol 2000;20:1699-1712.

30 Akat K, Mennel HD, Kremer P, et al. Molecular characterization of desmosomes in meningiomas and arachnoidal tissue. Acta Neuropathol 2003;106: 337-347.

31 Rooprai HK, Liyanage K, Robinson SF, et al. Extracellular matrix-modulated differential invasion of human meningioma cell lines in vitro. Neurosci Lett 1999;263:214-216.

32 Jensen RL, Leppla D, Rokosz N, et al. Matrigel augments xenograft transplantation of meningioma cells into athymic mice. Neurosurgery 1998;42: 130-135.

33 Jensen RL, Wurster RD. Calcium channel antagonists inhibit growth of subcutaneous xenograft meningiomas in nude mice. Surg Neurol 2001;55: 275-283.

34 McCutcheon IE, Friend KE, Gerdes TM, et al. Intracranial injection of human meningioma cells in athymic mice: an orthotopic model for meningioma growth. J Neurosurg 2000;92:306-314.

35 Kalamarides M, Niwa-Kawakita M, Leblois $\mathrm{H}$, et al. Nf2 gene inactivation in arachnoidal cells is ratelimiting for meningioma development in the mouse. Genes Dev 2002;16:1060-1065. 